\title{
FLAME SHAPES AND HEAT TRANSFER CHARACTERISTICS OF AN IMPINGING FLAME JET
}

\author{
Shankar Badiger ${ }^{1}$, T.R. Anil ${ }^{2}$, V.V.Katti ${ }^{3}$ \\ ${ }^{1}$ AssistantProfessor,KLS, VDRIT, Haliyal,Karnataka, India; \\ ${ }^{2}$ Professor, KLS, GIT, Belgaum,Karnataka,India; \\ ${ }^{3}$ Principal, KLS, VDRIT, Haliyal,Karnataka, India;
}

\begin{abstract}
Experiments were conducted on premixed LPG/air circular flame jet impinging normally on a rectangular flat surface. The heat transfer characteristics and flame shapes have been studied by varying the different parameters like equivalence ratio $(0.8,1,1.2$ and 1.4) and Reynolds number (500,600,800, 1000, 1200 and 1500). A circular flame jet impinged on to water cooled calorimeter made up of spiral rings. The increase in the height of the fame was observed by increasing both Reynolds number and equivalence ratio. The heat flux was increased by increasing the Reynolds number and also by increasing equivalence ratio.
\end{abstract}

Keywords: Premixed LPG /Air Combustion; Flame Shapes; Impingement Heat Transfer

\section{INTRODUCTION}

Impinging jets have wide range of applications in melting the scrap, heating metal bars, shaping the glass, drying of industrial material and domestic purposes. Flame jets are also used in breaking under sea rocks, cutting steel plates, concretes and ceramics to dismantle underwater structures.

S.G.Tuttle et al. [1] studied axial and radial profiles of timeaveraged local heat flux of Methane-air jet flames impinging to a cooled plate by changing the equivalence ratio, Reynolds number and nozzle-plate placing. L.L.Dong et al. [2] conducted experiment to study the heat transfer characteristics of a premixed butane/air slot flame jet impinging on a rectangular plate by varying the Reynolds number and nozzle to plate distance. X.Q.Huang et al. [3] investigated the heat transfer characteristics by a premixed impinging laminar flame jet with induced swirl by varying Reynolds number and nozzle to plate distance. Z.Zhao et al. [4] used an array of three premixed butane-air fired impinging circular flames with induced swirl to identify heat transfer characteristics. C.E.Baukal and B.Gebhart[5] investigated heat transfer from oxygen-enhanced/natural gas flames impinging on a plate.

SubhashChander and Anjan Ray [6] conducted experiment to study heat flux distribution of the target plate by three interacting Methane-air flame jest(arranged in a triangular configuration).H.S.Zhen et al.[7] investigated heat transfer behaviour of an annular jet flame impinging to a flat plate for different Reynolds number, equivalence ratio and nozzle to plate distance. It has been observed that peak heat flux occurs at a radial position at small nozzle to plate distance and increase in the nozzle to plate distance, heat flux coincides with jet axis. Naeem Khan et al.[8] studied jet diffusion flames fuelled by a LPG and Hydrogen. The flame height, lift-off velocity and lift-off heights were studied.Wei-Dong Hsieh and Ta-Hui Lin[9] conducted experiments and studied flame jet stability impinging onto a wall for different equivalenceratio, burner to plate distance, inlet velocity and inlet fuel concentration.From literature it has been observed that, there are few studies focused on flame shapes, therefore, the objectives of present work is to study the flame shapes and also heat transfer characteristics of an impinging flame jet on to a wall. The equivalence ratio and Reynolds number are varied to study the flame shapes and heat transfer rate.

\begin{tabular}{|ll|}
\hline Nomenclature & \\
$\mathrm{Re}$ & Reynolds number \\
$\mathrm{m}$ & Mass flow rate $(\mathrm{kg} / \mathrm{s})$ \\
$\mathrm{d}$ & Diameter of nozzle $(\mathrm{m})$ \\
$\mu$ & Dynamic viscosity $(\mathrm{Cp})$ \\
$\mathrm{y}$ & Mole fraction \\
$\mathrm{M}$ & Molecular weight \\
$\mathrm{A} / \mathrm{F}$ & Air-to-fuel ratio \\
$\varnothing$ & Equivalence ratio \\
$\mathrm{q}$ & Average heat flux $\left(\mathrm{kW} / \mathrm{m}^{2}\right)$ \\
$\mathrm{T} 1$ & Inlet temperature of cooling \\
& water(K) \\
$\mathrm{T} 2$ & Outlet temperature \\
& cooling water $(\mathrm{K})$ \\
& \\
Subscriptions & \\
mix & Air/fuel mixer \\
$\mathrm{i}$ & Mixture component of fuel \\
stoic & and gas \\
\hline
\end{tabular}

\section{EXPERIMENTAL SET-UP}

Fig. 1 shows schematically the experimental set-up to capture the flame shapes and measuring the average heat flux. The 
$10 \mathrm{~mm}$ nozzle diameter burner has been employed to produce circular flame. The nozzle was fixed to a mixing chamber where various sized steel balls have been introduced for proper mixing of fuel and air. The screen mesh has been attached above the steel balls in the nozzle to avoid the flashback of the flame. The calorimeter was fabricated with copper plate of $6 \mathrm{~mm}$ thickness. The copper was selected as target plate material because of its maximum thermal conductivity. The spherical channels have been made on the copper plate to circulate cooling water to acquire heat transfer data. The designed, fabricated and calibrated orifice meters have been used to adjust the

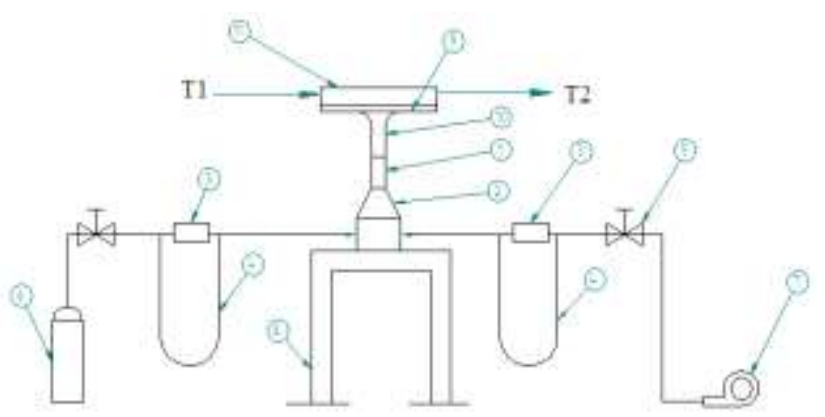

Fig.1. Schematic of experimental setup.
1. Nozzle
2.Burne
3. Orifice meter

4. U -Tube manometer 5. Control valve

6. LPG Cylinder 7. Compressed air line 8. Steel frame

9. Target plate 10. Flame jet 11.Calorimeter

flow rate of LPG fuel and air according to the Reynolds number and equivalence ratio selected. The calibrated K-type thermocouples were used to record the calorimeter temperatures.

\section{DATA REDUCTION}

For the flame jet, exit Reynolds number was calculated based on air/fuel mixer as

$$
\operatorname{Re}=\frac{4 \mathrm{~m}_{\text {mix }}}{\pi \mathrm{d} \mu_{\text {mix }}} .
$$

Dynamic viscosity of mixture was calculated according to Ikoku [10] as

$\mu_{\text {mix }}=\frac{\Sigma\left(\mu_{\mathrm{i}} \mathrm{y}_{\mathrm{i}} \sqrt{\mathrm{M}_{\mathrm{i}}}\right)}{\Sigma\left(\mathrm{y}_{\mathrm{i}} \sqrt{\mathrm{M}_{\mathrm{i}}}\right)}$

Equivalence ratio was calculated by

$$
\emptyset=\frac{(\mathbf{A} / \mathbf{F})_{\text {stoic }}}{(\mathbf{A} / \mathbf{F})_{\text {actual }}}
$$

\section{EXPERIMENTAL PROCEDURE}

For the selected Reynolds number and equivalence ratio, the metered quantity of air and fuel was supplied to the mixing chamber of the burner. The calibrated orifice meters were used to ensure the supply of fuel/air mixture to the burner
(Fig.1). The water with a temperature of $40^{\circ} \mathrm{C}$ was circulated to the calorimeter as a cooling agent to prevent the condensation of moisture in the products of combustion at the target plate. Readings were taken under the steady state

conditions. The experiments were conducted to capture the flame shapes and to record the heat fluxes by varying both equivalence ratio $(0.8,1,1.2$, and 1.4) and Reynolds number $(500,600,800,1000,1200$ and 1500). The distance between the nozzle and the target plate was kept constant $(50 \mathrm{~mm})$.

\section{RESULTS AND DISCUSSION}

Flame shapes and heat transfer characteristics of LPG flame jet impinging on to a flat surface have been studied. The effects of parameters like equivalence ratio and Reynolds number are studied here by keeping the nozzle to plate distance constant.

\subsection{Flame shapes}

Fig. 2 to fig.5 shows the different flame structure against different Reynolds number and equivalence ratio. The nozzle to plate distance was kept constant and is $50 \mathrm{~mm}$. For all the Reynolds number and equivalence ratio, the inner reaction cone (bright blue colour) and outer blue envelope was observed. It is has been observed that, flame height gradually increased as the Reynolds number increases. This is because increase in the Reynolds number means both fuel and air quantity increases.

With increase in the equivalence ratio and Reynolds number, the wall jet flame increases in size while the flame at the free jet remains unchanged At 800 Reynolds number, wall jet region begins to start and further increase in the wall jet region can be seen as the Reynolds number increased. The increase in the height of central cone can be observed as Reynolds number and equivalence ratio increases. The central cone of the flame touches the target plate at the equivalence ratio $\emptyset=1.2$ and 1.4 .
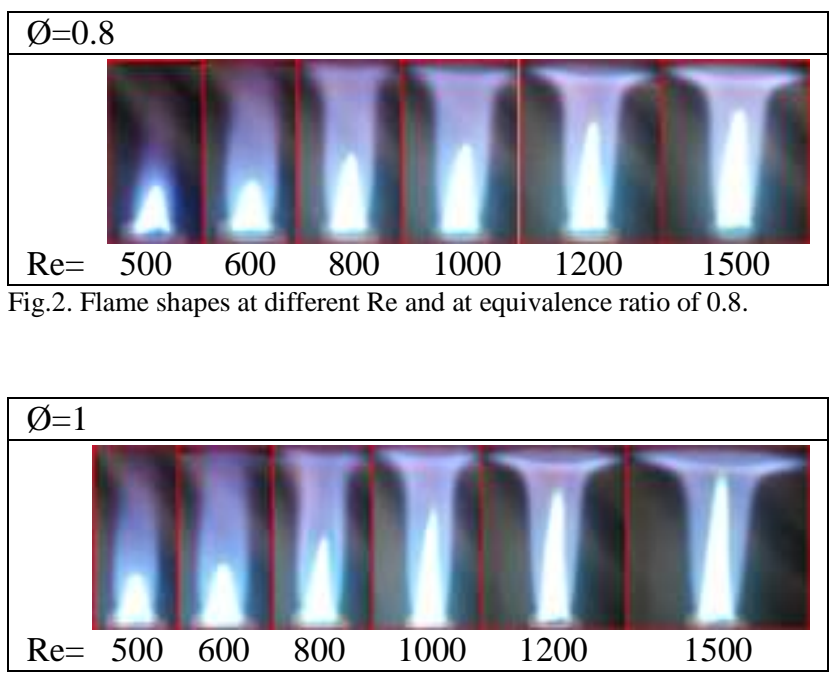

Fig.3. Flame shapes at different $\mathrm{Re}$ and at equivalence ratio of 1 . 


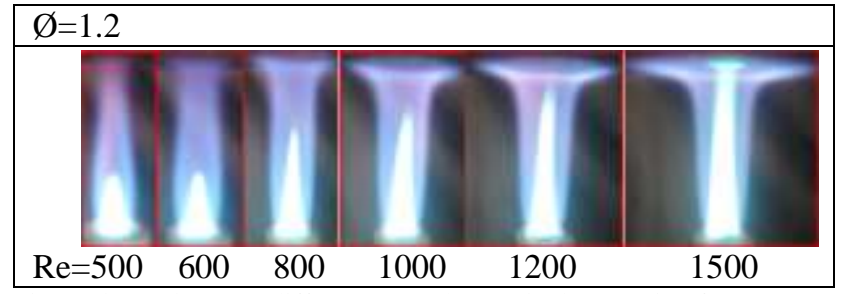

Fig.4. Flame shapes at different Re and at equivalence ratio of 1.2 .

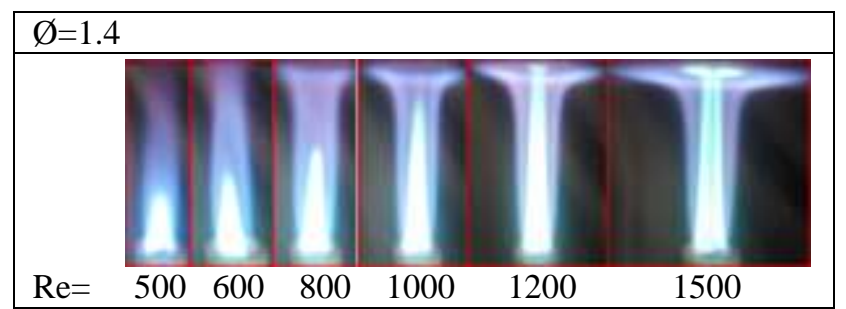

Fig.5.Flame shapes at different Re and at equivalence ratio of 1.4.

\subsection{Heat flux}

The experiments were conducted against the different Reynolds number and the equivalence ratio. The heat fluxes were obtained for different equivalence ratio $(0.8,1,1.2$ and 1.4) and different Reynolds number (500, 600, 800, 1000, 1200 and 1500). Fig. 6 to fig.9 depicts the variation of heat flux under different Reynolds number and different equivalence ratio. It can be seen that there is increase in heat flux as the Reynolds number increases. This is because the increase in the Reynolds number increases both the supply of fuel and air quantity. Similar trend has been observed for higher Re [7]. Large amount of fuel is burnt and impinges on the target plate. For the Reynolds number 600 onwards, there is a formation of wall jet region. Even though impingement of cool central core (see fig. 2 to 5) to the target plate, there is an increase in heat flux because the large amount of fuel which is pushed away radially outward and burning of that fuel releases the heat to the target plate. Fig. 10 shows the comparison of heat fluxes under different Reynolds number and at different equivalence ration. Increase in the heat fluxes observed by increasing the equivalence ratio. This is because more amount of fuel is emitted from the nozzle.

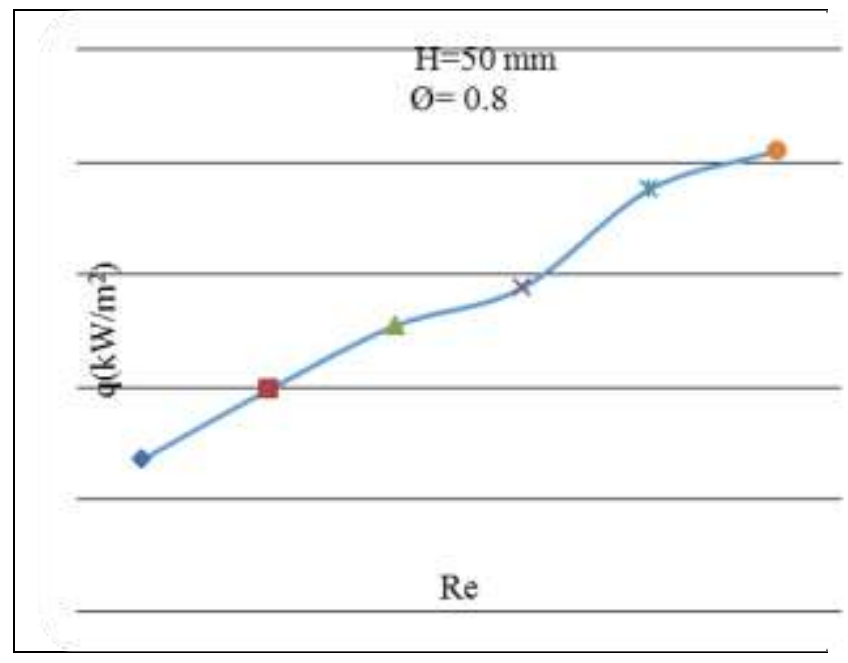

Fig.6. Variation of heat flux under different Reynolds numbers $(\varnothing=0.8$, $\mathrm{H}=50 \mathrm{~mm})$.

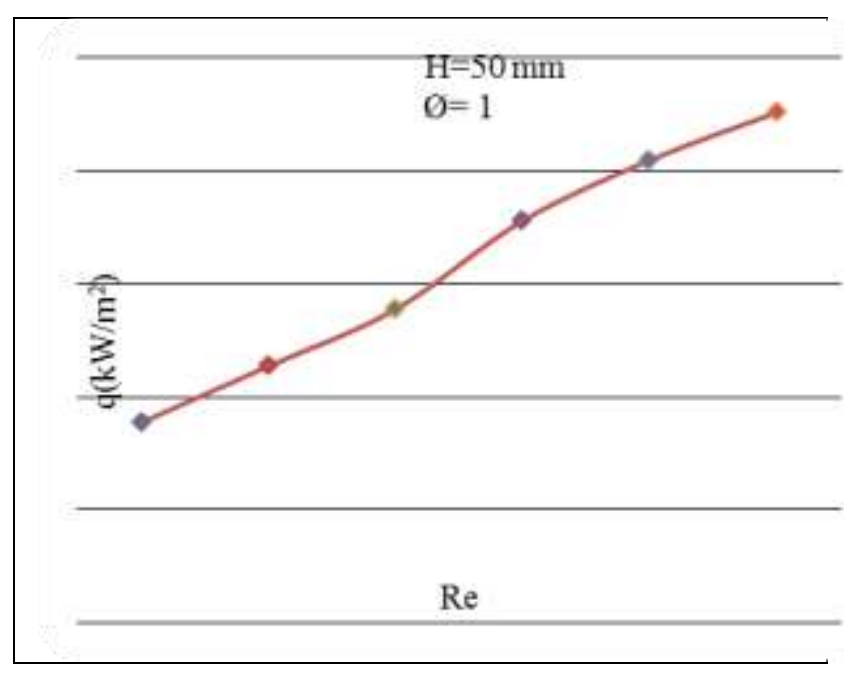

Fig.7. Variation of heat flux under different Reynolds numbers $(\varnothing=1$, $\mathrm{H}=50 \mathrm{~mm})$.

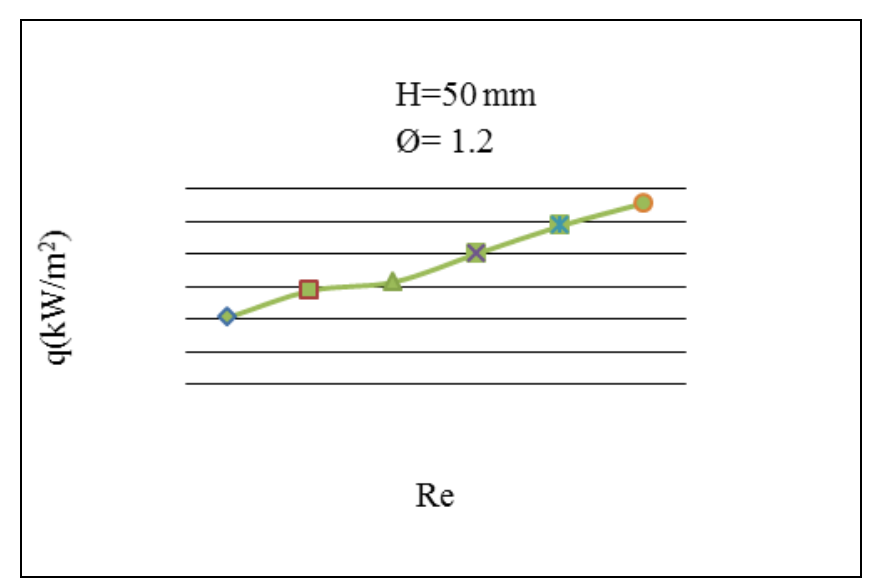

Fig.8.Variation of heat flux under different Reynolds numbers $(\varnothing=1.2$, $\mathrm{H}=50 \mathrm{~mm})$. 


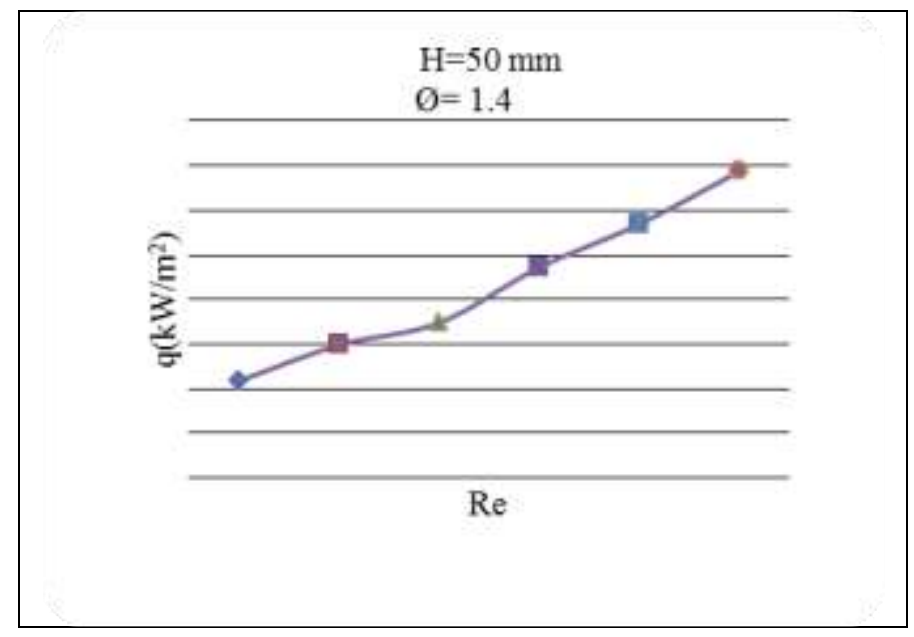

Fig.9.Variation of heat flux under different Reynolds numbers $(\varnothing=0.4$, $\mathrm{H}=50 \mathrm{~mm})$.

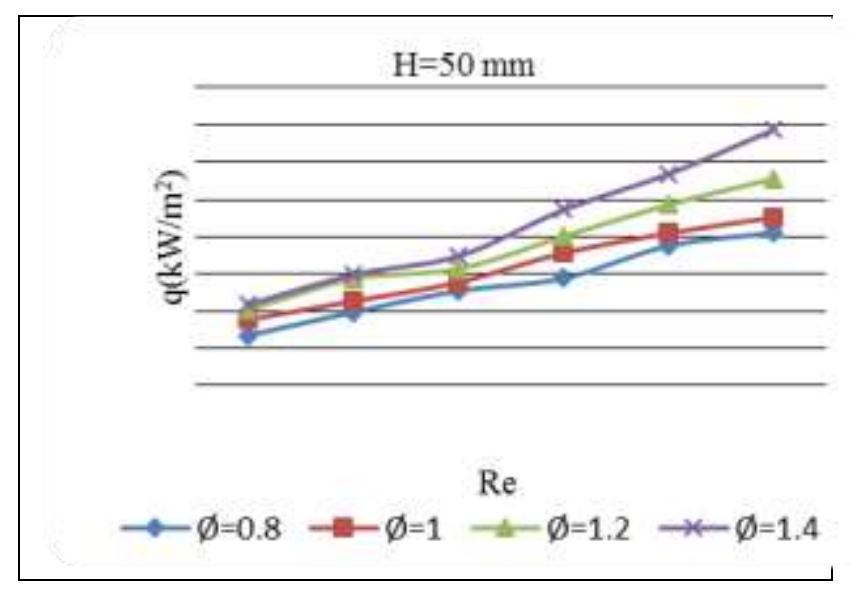

Fig.10.Comparision of heat flux under different Reynolds numbers $(\varnothing=0.8$, $1,1.2,1.4 \& \mathrm{H}=50 \mathrm{~mm})$.

\section{CONCLUSION}

Experiments were conducted to study the flame shapes and heat transfer characteristics of circular premixed LPG/air flame jet impinging on a flat surface. The Reynolds number and equivalence ratio were varied to study the effects on flame shapes and heat transfer rate. The nozzle to plate [7] H.S.Zhen, C.W.Leung, C.S.Cheung, Heat transfer characteristics of an

impinging premixed annular flame jet, Applied Thermal Engineering 36(2012)386-392.

[8] Naeem Khan, K.R.V.Manikantachari, Rahul Dutta Roy, V.Raghavan, Experimental study of characteristics of LPGhudrogen jet diffusion flames, Asian Journal of Scientific research 6(2)(2013)227-235.

[9]Wei-Dong Hsieb, Ta-Hui Lin, Methane flame stability in a jet impinging onto a wall, Energy Conversion and Management 46(2005)727-739.

[10] C.U.Ikoku, Natural Gas Production Engineering, 1984, pp. 58-60. distance was maintained constant. Based on the results, the following conclusions were made.

- Inner reaction cone and outer envelope has been observed for all the Reynolds number and equivalence ratio.

- Increase in the Reynolds number increased the height of the flame.

- For the Reynolds number of 800, 1000, 1200 and 1500 there was observation of stagnation region and wall jet region. But the size of free jet remained same.

- Increase in the heat flux has been observed as the Reynolds number increases.

- Maximum heat flux has been observed for higher the equivalence ratio $\emptyset=1.4$.

\section{REFERENCES}

[1] S.G. Tuttle, B.W.Webb, M.Q.McQuuay. Convective heat transfer from a partially premixed impinging flame jet, Int.J.Heat Mass Transfer 48(2005)1236-1251.

[2] L.L.Dong, C.S.Cheung, C.W.Leung. Heat transfer from an impinging premixed butane/air slot flame jet, Int.J.Heat Mass Transfer 45(2002)979-992.

[3] X.Q.Huang, C.W.Leung, C.K.Chan, S.D.Probert, Thermal characteristics of a premixed impinging circular laminar-flame jet with induced swirl, Applied Energy 83(2006)401-411.

[4] Z.Zhao, D.W.Yuen, C.W.Leung, T.T.Wong, Thermal performance of a premixed impinging circular flame jet array with induced swirl, Applied Thermal Engeineering 29(2009)159-166.

[5] C.E.Baukal, B.Gebhart, Heat transfer from oxygenenhanced /natural gas flames impinging normal to a plane surface, Experimental Thermal and Fluid Science 16(1998)247-259. 